instruction of students and junior staff in this most common and important procedure. -We are, etc.,

J. G. R. Howie.
R. L. C. CUMming.
Department of Medicine,
Gardiner Institute,
Western Infirmary,
Glasgow W.1.
Reference
Howie, J. G. R., and Cumming, R. L. C.,

\section{Multiple Choice Examinations}

SIR,-I was intrigued that my last "Personal View" article (17 May, p. 443) was described (31 May, pp. 572 and 573) by those who wanted to dismiss its main point as being on the one hand "pungent" (Dr. W. F. M. Wallace) and on the other "a jolly little article" (Professor J. N. Hawthorne). Dr. W. K. Cowan at least found it "humane," for which adjective I was grateful. The first two attacked mainly the phrase I used to express my concern for first-class candidates. Anti-intellectualism is only too common, it seems to me, in our medical schools. Now first-class men represcnt only about $10 \%$ of those reading for honours degrees (at least in this university).

May I make it clear that my major concern and interest, in both teaching and examining, is with the others, those "middleof-the-road men," who are the backbone of the profession and the salt of the earth ? In my experience the ordinary, generousminded student is as glad to recognize the qualities of the outstanding man as are some, but certainly not all, university examiners. I think it is essential that these gifted individuals should be allowed to show their gifts, and make fools, if need be, of their examiners This is something the multiple choice examination manifestly fails to allow. The really good man easily recognizes the ambiguities that are so often contained in both the question and in the "right" and the "wrong" answers. Unless he has confined his reading to the "permitted" text he is put at a real disadvantage, because he knows that under this or that circumstance this or that "answer" might be correct. $\mathrm{He}$ cannot demonstrate that he understands the subject better than his mentors do. This means the end of educational advance. Mediocrity is put at a premium. Admass is with us Professor Hawthorne put his finger on the point when he dealt with the problem of increasing numbors: "How," he asked, " can the university teacher (who is also supposed to be actively engaged in research) possibly manage without the aid of computer marking ?" Well, each must answer for himself. Expediency is important, but not allimportant.

If increasing numbers lead inevitably to declining standards (" more meaning worse," to paraphrase Kingsley Amis's celebrated phrase), then there is something wrong with the system. It was the system that I was criticizing. I shall go on doing so whenever it produces a deceitful and anti-intellectual " solution," such as I believe the M.C.Q. method to be.-I am, etc.,

School of Anatomy,

BERNARD TOWERS.

\section{Auditory Testing in Infants}

SIR,--Experience during the past five years has clearly demonstrated the usefulness of screening tests of hearing in infants. These tests should be an integral part of the work at infant welfare clinics. Few people will doubt that early detection of deafness makes all the difference as far as successful rehabilitation is concerned.

The methods of screen testing are comparatively simple. Selected test sounds are produced at very small intensities and a reaction of the baby is observed, the reaction being by turn of the head towards the source of the sound. The most important condition for satisfactory testing is a quiet environment. The quieter this environment the greater the probability becomes of noticing a small sudden change, in this case a sound. Unless these tests are carried out in conditions below a certain noise level the intensity of the test sound merges in the background noise and it becomes insignificant.

One must emphasize that it is impossible to carry out satisfactory hearing tests in a noisy place. No one would try to test the vision of a child in a dark room in which one is unable to see the test material. Yet many people are quite prepared to test hearing in acoustic " darkness."

Few infant welfare clinics have a quiet room where these tests can be carried ou satisfactorily. This is now the greatest obstacle to implementing a successful programme for the early detection of deafness. It is particularly disturbing to find that new clinics continue to be planned and built with cut a quiet room. Financial consideration do not appear to be the reason for the failure to provide this accommodation, but rather a complete lack of understanding by local authorities of the importance of incorporating a quiet room in all clinic buildings.- I am, etc.,

$$
\begin{aligned}
& \text { Hearing Clinic, } \\
& \text { Heston, Middx. }
\end{aligned}
$$$$
\text { L. FisCH }
$$

\section{Drug Treatment of Thyrotoxicosis}

SIR,-We feel we must challenge the statement that "propranolol . . . is generally less effective than reserpine and guanethidine" in controlling the peripheral manifestation of thyrotoxicosis, which was included in "Drug Treatment of Thyrotoxicosis" (24 May, p. 496). We respect the fact that there is individual variation in the management of thyrotoxicosis, but to our knowledge there has been no published study comparing the effects of sympathetic antagonists such as reserpine and guanethidine with beta-adrenergic receptor blocking drugs such as propranolol in controlling many of the clinical features of thyrotoxicosis.

It has been shown that oral or intramuscular adminictration of resenpine reduces many of the features of thyrotoxicosis. However, nearly three weeks may elapse before improvement or alleviation of symptoms is achieved by oral therapy. On intramuscular administration side-effects such as weakness, dizziness, nasal stuffiness, headache, and insomnia were frequently noted, and nervousness and tremor were aggravated. Several studies have shown that guanethidise is also effective, ${ }^{2} 3$ but on oral administration six days was the average time taken for a good response, and hypotension, which is posture dependent, occurred in several patients. It should be pointed out, however, that none of these trials were double-blind. We have now used propranolol in over 100 patients with thyrotoxicosis as an adjunct to therapy with radioactive iodine, carbimazole, and in preoperative preparation for surgery. Propranolol produced marked reduction in the features of the disease within 24 hours of oral administration of the first dose. In a controlled double-blind trial in patients with thyrotoxicosis, ${ }^{4}$ propranolol (40 mg. four times daily) was shown to be significantly better, on sequential analysis, in producing subjective and objective improvement in the clinical features of thyrotoxicosis than a placebo. In this trial and in all our patients we have experienced no side-effects from the administration of propranolol.

Other workers have shown that propranolol is extremely effective in the control of thyroid crisis. $^{5-7}$ McLean ${ }^{5}$ found that his patient responded better to propranolol than to reserpine or guanethidine. It may be that betaadrenergic receptor blocking drugs have an advantage over reserpine and guanethidine in that they avoid any undesirable central nervous system effects of reserpine and the postural hypotension of guanethidine.

This article again emphasizes the shortcomings of "Today's Drugs" and some leading articles in the British Medical Fournal to which attention has been recently drawn by Dr. A. M. Barrett (1 February, p. 318) and Dr. G. M. Wilkinson (17 May, p. 446). Statements, such as the one we criticize, must be supported by references and must not be clinical impressions of the author. If these articles are to be of real value they must be backed by full references, must be up to date, and should preferably be signed by the author. Although several papers have appeared recently describing the use of propranolol in thyrotoxicosis, no mention was made of these.-We are, etc.,

D. A. D. Montgomery.

D. C. LowE.

R. G. SHANks.

J. A. WEAVER.

Royal Victoria Hospital,

REFERENCES

1 Canary, J. J., Schaaf M., Duffy, B. J., and cine, 1957, 257, 435

Lee, W. Y., Bronsky, D., and Waldstein, S. S. fournal of Clinical Endocrinology and Metisbolism, 1962, 22,879.

Waldstein, S. S., West, G. H., jun., Lee, W. Y. and Bronsky, D., fournal of the American Medical Association, 1964, 189, 609 .

Shanks, R. G., Hadden, D. R., Lowe, D. C. McDevitt, D. G., and Montgomery, D. A D. Lancet, $1969,1,993$

Medical fournal of Australia. 1967, 2, 229

arsons, V., and Jewitt, D., Postgraduate Medical Buckle, R. M., Acta Endocrinologica, 1968, 57 , 168.

\section{Varicose Veins, Cotton Workers, and Diet}

SIR,-With reference to the paper by Siz: Mekky and others ( 7 June, p. 591) our work would indicate that the factors advanced by the writers are essentially aggravating factors of a deeper-lying primary cause, without which they would not be abie to produce varicose veins at all. Some of these factors, for example, can clearly have no reference to the varicose veins occurring in men.

Believing as I do that the primary cause of varicose veins is a weighted colon, arising from the consumption of refined carbohydrates and impeding the blood return from the lower limbs, I regret that the writers did 
not refer to the diet in their Egyptian subjects, nor to the nature of the stools that reflects this diet. Personal statements about regularity, etc., are unreliable, for the stools may be passed always one or two days late, but the diameter of the formed stool is of great value. In our African subjects, who are virtually free from varicose veins, the stools are characteristically narrow in diameter, with transit times about two days less than in people on a Westernized diet ${ }^{2}$ (and the squatting position in these Africans could not be implicated, because there is no straining, whatever the position adopted-the stools in fact being passed twice daily).

The carbohydrates consumed in lower Egypt include much unrefined maize, but also refined rice, whereas in northern Egypt the diet is based on unrefined millet and (in the Bedouin) unrefined barley. If these northern Egyptians were studied, still living on their traditional foods, I am confident that the incidence of varicose veins would be found still lower-in fact probably zero. -I am, etc.,

Fareham, Hants.

$$
\text { T. L. Cleave. }
$$

\section{REPERENCES} Cleave, T T. L., Campbell, G. D., and Painter,
N. S., Diabetes, Coronary Thrombosis and the Saccharine Disease, 2nd ed. John Wright. Campbell, G. D., and Cleave, T. L., British Medical Gournal, 1968, 3,74i.

\section{Sacrococcygeal Chordoma}

SIR,-Chordomas are rare neoplasms which arise from notochordal remnants along the cerebrospinal axis. More than a hundred years ago Virchow described a tumour of the basisphenoid seen at necropsy. In 1856 von Luschka described a similar tumour while Müller two years later described yet another case and proposed its notochordal origin.

They occur most commonly at the extremes of the cerebrospinal axis. Growth is slow, with extension of the tumour to adjacent structures. Symptoms can be of long duration and they vary with the site of origin. Almost invariably total removal is impossible, and recurrence is the rule. Metastases are very uncommon. Our own patient had an unusually large chordoma which was followed for 14 years.

A 50-year-old farmer presented at the outpatient orthopaedic clinic of Athens University in February 1965, complaining of constipation and not surprisingly difficulty in walking and other daily activities. He had first presented in 195 with sacral pain and a palpable and visible mass in the gluteal area. Its size at that time was not recorded, but noted only as "small." Routine investigation, including $x$-rays but excluding biopsy, was normal, and no treatment was instituted. He returned three years later complaining that the mass was increasing in size and was further impairing his ability to walk. His constipation was increasing to obstipation with occasional bloodstained stools. His general health remained good. No further investigation or treat ment was begun at this time. He returned in 1960 with the same complaints, and it was noted that the mass had increased considerably in size. No biopsy was carried out, but the patient had a 40 -dose course of $x$-irradiation which alleviated his pain and, according to his opinion, arrested growth of the mass for a short period of time. Irradiation was repeated in 1961 and 1962, each time with 20 exposures, with relief of the recurrent pain on both occasions.
In 1963 a perforated gastric ulcer was repaired surgically and further growth of the mass was noted at that time, but the patient was pain-free and remained so until 1965, when he presented with yet again a recurrence of his pain. The size and extent of the mass were as seen in the Figures. $\mathrm{He}$ complained of very marked constipation and inability to lie on his back. Walking and bending were increasingly difficult. The inass was firm and fixed to the pelvis and sacrum, but was non-tender. Firm, mobile inguinal lymph nodes $1 \mathrm{~cm}$. in diameter were palpable. Grossly distended veins were visible over the tumour mass and in both legs. Radiographs of the pelvis showed a large osteolytic lesion of the sacrum with numerous radio-opaque deposits in the tumour mass. Histological examination of a biopsy specimen proved chordoma.

No treatment was given, because surgical excision seemed impossible, especially in view

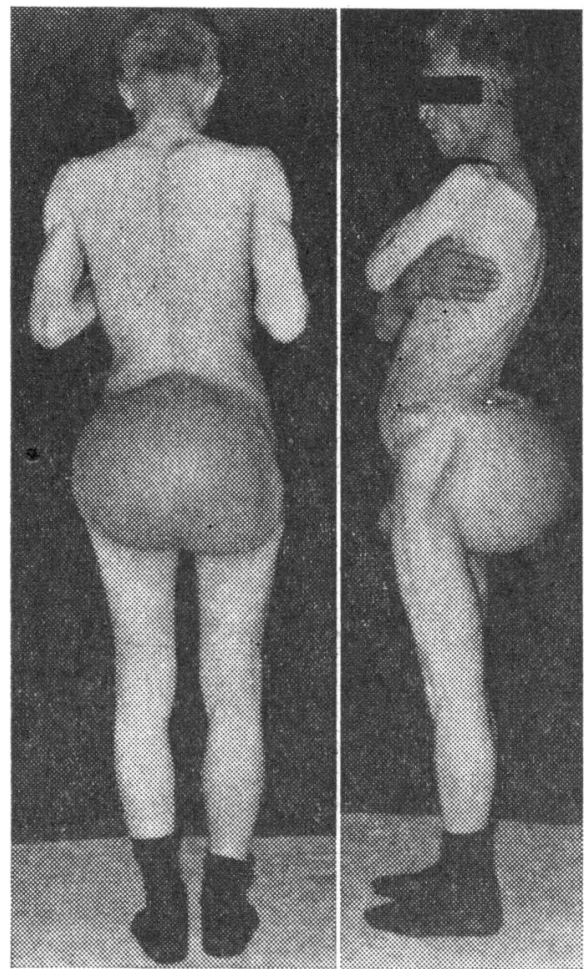

of the vascularity encountered at biopsy. The patient continues to be ambulatory with his previous complaints and his activities markedly curtailed.-We are, etc.,

\section{G. Harto-Garofalidis \\ G. KAMBOUROGLU. \\ E. G. Fragiadakis}

University Orthopaedic Clinic,

Athens, Greece.

\section{Radiology's New Chance}

SIR,-May I comment on your leading article "Radiology's New Chance" (24 May, p. 464) and support many of the points in the correspondence from Professor J. H. Middlemiss and Dr. R. G. Grainger (14 June, p. 692).

There is an urgent need to establish academic departments of radiology in university centres. At present the teaching of radiology to undergraduates and postgraduates depends on the initiative and enthusiasm of clinical radiologists. Their service work-load is heavy, and the continuing rise appears to be inevitable. There is a real need for specific time to be set aside for academic duties in teaching and collaborative research.

An investigation into the shortage of hospital radiologists in New Zealand by a subcommittee of the College of Radiologists of Australasia succinctly describes a current problem. Peripheral staffing is completely dependent on metropolitan recruitment. Such recruitment depends on the image presented by the radiologists to potential recruits. To perpetuate the image of an overcrowded, overworked, understaffed specialty in the main centres will inevitably depress recruitment and aggravate the shortage. It is not surprising to read of Dr. Grainger's observations at first hand of the value of a virile academic department, and that up to $25 \%$ of final-year medical students apply for a career training in radiology. This is in sharp contrast to the Report of the Royal Commission on Medical Education, ${ }^{1}$ which states that $0.3 \%$ of first year students gave radiology as their first choice and this increased to only $0.8 \%$ at the end of the fifth year. There is no doubt that a more vigorous approach will help to improve recruitment. At the integrated year lectures at the Western Infirmary it was very interesting and rewarding to find that $29.5 \%$ of fourth year undergraduates considered aaking up diagnostic radiology as a career. Certainly this observation was obtained shortly after a series of seminars and videotape demonstrations on radiology, ${ }^{2}$ and this must influence the results.

There are many enthusiastic and able clinical radiologists in this country who would welcome the opportunity of working in or being associated with academic departments.-I am, etc.,

$$
\begin{aligned}
& \text { Western Infirmary, } \\
& \text { Glasgow } \mathbb{W} .1 . \\
& \text { REFERENCES } \\
& \text { Royal Commission on Medical Education, 1965- } \\
& 68 \text { : Report, 1968. Cmnd. } 3569 \text {. London, } \\
& \text { H.M.S.O. } \\
& \text { Davidson, J. K., and Thomson, G. B., British } \\
& \text { fournal of Medical Education (in press). }
\end{aligned}
$$

\section{An Ingenious Munchausen}

SIR,-The "ingenious Munchausen" described by Dr. D. R. Seaton (3 August 1968, p. 317) and Dr. J. M. Malins and Dr. P. J. Watkins (31 August 1968, p. 554) has continued to move northwards. He arrived on 9 June 1969 at Aberdeen Royal Infirmary accident unit and was later admitted to this hospital. His history had changed a little, but certain similarities left us in no doubt that we were dealing with the same man. He described himself as a Rhodesian working as a pilot with a small Rhodesian air company but at present on vacation. He claimed that a cystoscopy in Paris 10 days previously had shown "granulated lesions and ulcers" in the bladder, but no biopsy had been taken. His complaint on his admission was of "excruciating" perineal pain and continuing haematuria, which he said was due to a recurrence of schistosomiasis for which he had been treated on two previous occasions. He claimed to have been a mercenary in the Congo, where he had a haematemesis, which he inferred resulted from 